International Journal of Advanced Trends in Computer Science and Engineering

Available Online at http://www.warse.org/IJATCSE/static/pdf/file/ijatcse376942020.pdf

https://doi.org/10.30534/ijatcse/2020/376942020

\title{
The Kinetic Study of DPT Using Mathematica as an Efficient Optimization Tool
}

\author{
M. H. El Dewaik ${ }^{1}$, Mamdouh Gadalla ${ }^{2,3}$, M. A. $\operatorname{Radwan}^{2}$, M. A. Sadek ${ }^{2}$, Hany A. Elazab ${ }^{2,4 *}$ \\ ${ }^{1}$ Department of Basic Science, The British University in Egypt, El-Shorouk City, Cairo, Egypt. \\ ${ }^{2}$ Department of Chemical Engineering, The British University in Egypt, El-Shorouk City, Cairo, Egypt. \\ ${ }^{3}$ Department of Chemical Engineering, Faculty of Engineering, Port Said University, Egypt \\ ${ }^{4}$ Nanotechnology Research Centre (NTRC), the British University in Egypt (BUE), El-Sherouk City, Suez Desert \\ Road, Cairo, 11837, Egypt. \\ * Corresponding Author: elazabha@vcu.edu
}

\begin{abstract}
Mathematica is a powerful program for computing both numeric and algebraic calculations as well as graphing two and three dimensional curves and surfaces. It is used increasingly in many fields of science now such as physics, engineering, chemistry and even biology because of the fast interaction of mathematics with almost the fields of science nowadays. Synthesis of Cyclotetramethylene Tetramine through the action of nitrating mixture formed of ammonium nitrate and fuming nitric acid on hexamine in presence of acetic acid, acetic anhydride and $\mathrm{p}$-formaldehyde has been proven. The pathway is relatively long and Hexamine Dinitrate and Dinitro Pentamethylene Tetramine (DPT) are two of the main intermediate compounds. The former was prepared, purified, and then characterized. Conversion of this compound into the latter has been followed up experimentally. Herein, we report the Preparation of Dinitro Pentamethylene Tetramine (DPT) from Hexamine Dinitrate as an alternative synthetic route - which is an important intermediate appears through preparation of DPT from Hexamine directly. DPT was prepared at different temperatures. The variation of some factors like: temperature and time has been investigated. The obtained results were reliable and consistent with the literature. The conversion of Hexamine Dinitrate to HMX as another synthetic route was not fully studied from the point of view of kinetics. In this paper, it is intended to study the effect of time and temperature on the conversion rate of hexamine dinitrate to DPT. This scientific approach is considered as a bridge through which we aim to initiate a complete kinetic study of an important intermediate in the synthesis route of one of the most powerful energetic materials.

We report here, optimizing the kinetic data for the synthesis of DPT via using Mathematica.
\end{abstract}

Key words: Mathematica, DPT; Kinetics, Optimization.

\section{INTRODUCTION}

Energetic materials such as explosives, propellants and pyrotechnics are widely used for both civilian and military applications. Design of future defense systems requires the use of energetic material formulations having enhanced performance (energy output) and reduced vulnerability during manufacturing, handling, storage and transportation. Several important design considerations for such formulations include improved mechanical properties, extended service life and reduced environmental impact in manufacture, use and disposal [1]. Energetic materials are substances or mixtures that react chemically to release energy required for their intended application.

Bachmann and Sheehan [2] developed a method of preparing DPT. This method involved nitrolysis of hexamine with ammonium nitrate - nitric acid solution and acetic anhydride.. [1-19]

Hexamine Dinitrate is an important raw material in production of DPT, hexogen (RDX) and HMX as a source of the methylene base and the simultaneously bound "anhydrous" nitric acid in an advantageous crystalline and relatively stable form [20-28]

HMX is considered as a powerful military explosive, but it has a limited use due to its high cost. Reported manufacturing processes for HMX involves the nitration of hexamine. It is well known that HMX can be prepared from DPT, which has been identified as a key intermediate in the formation of HMX from the nitration of hexamine, which is also known as the modified Bachmann process as previously mentioned.

The alteration of those previously mentioned parameters will lead to optimized process and hence obtain better results.[29-37]

Direct nitrolysis of 3,7-dinitro-1,3,5,7-tetraazabicyclo[38-45] nonane (DPT) is a feasible way to synthesize HMX, and it has multiple practical applications. A new nitrolysis process involving the use of an $\mathrm{N}_{2} \mathrm{O}_{5}-\mathrm{HNO}_{3}$ system catalyzed by acidic ionic liquids (AILs) was developed The effect of metallic ions on the nitrolysis of DAPT [3,7-diacetyl-1,3,5,7-tetraazabicyclo(3.3.1) nonane] and HA 
M. H. El Dewaik et al., International Journal of Advanced Trends in Computer Science and Engineering, 9(4), July - August 2020, 6774 - 6782

(hexamine) was investigated by experimental and theoretical approaches [45-69]

\section{EXPERIMENTAL}

Samples were prepared and filtered in a special fuming hood equipped with glass shelter and a powerful air suction system for ventilation. Safety regulations have been strictly applied. The preparation setup consisted of a flat-bottom $0.5 \mathrm{~L}$ flask equipped with a mechanical stirrer, three dropping funnels, and a thermometer. Filtration of the prepared samples was done using Buchner funnel - pump system. To handle these kinds of energetic materials, best safety practices (leather gloves, face shield) are strongly recommended. [45]

DPT was also prepared starting from the hexamine dinitrate. To a mixture formed of glacial acetic acid $(5 \mathrm{ml}, 0.0874 \mathrm{~mol})$ and acetic anhydride $(2 \mathrm{ml}, 0.0212 \mathrm{~mol})$, hexamine dinitrate $(1 \mathrm{~g}, 0.00375 \mathrm{~mol})$ was added as one portion. Then the reaction mixture was left, for a fifteen minute period, at a temperature of $\left(44 \pm 1^{\circ} \mathrm{C}\right)$ which was also maintained throughout this procedure. The reaction mixture was then quenched by chilling it to $12^{\circ} \mathrm{C}$. Rapid separation of the solid phase was then carried out.

\section{RESULTS AND DISCUSSION}

Mathematica is used to obtain more accurate and optimized results.

Table 1: DPT and hexamine dinitrate concentrations and concentration terms at different reaction times at $15^{\circ} \mathrm{C}$.

\begin{tabular}{c|ccccccccc}
\hline $\begin{array}{c}\text { Time } \\
(\text { min. })\end{array}$ & 0 & 5 & 10 & 15 & 120 & 240 & 360 & 480 & 600 \\
\hline $\begin{array}{c}\text { Hexamine } \\
\text { dinitrate } \\
(\mathrm{mg} / \mathrm{ml})\end{array}$ & 0.592 & 0.589 & 0.587 & 0.583 & 0.541 & 0.480 & 0.44791 & 0.385 & 0.355 \\
\hline $\begin{array}{c}\text { DPT }(\mathrm{mg} / \\
\mathrm{ml})\end{array}$ & 0 & 0.001 & 0.002 & 0.005 & 0.032 & 0.072 & 0.10200 & 0.126 & 0.135 \\
\hline
\end{tabular}

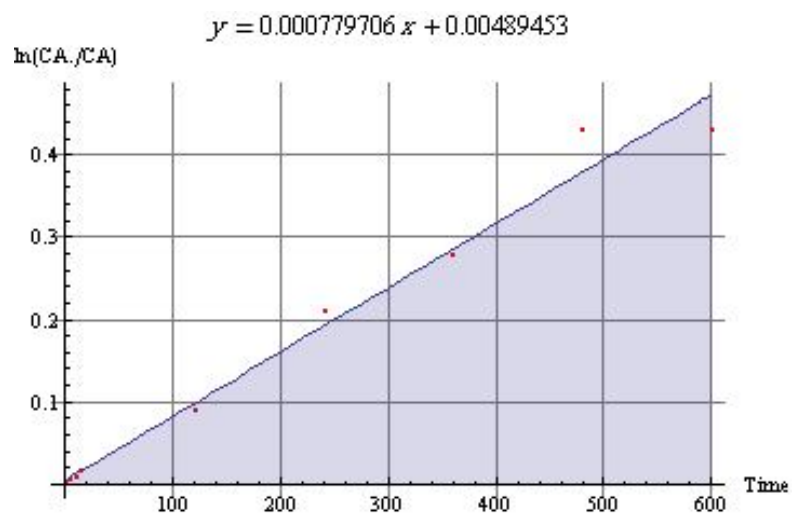

Figure. 1: Representation of the hexamine dinitrate concentration-time data at $15^{\circ} \mathrm{C}$ - First Order, $\mathrm{R}^{2}=0.997832$.
The arte constant is simply calculated from the obtained concentration results as shown in Figure 1 based on the calculated results from Table 1. [45]

The reaction is generally very slow. 600 minutes were sufficient to convert about $40 \%$ only from hexamine dinitrate into DPT as shown in Table 1.

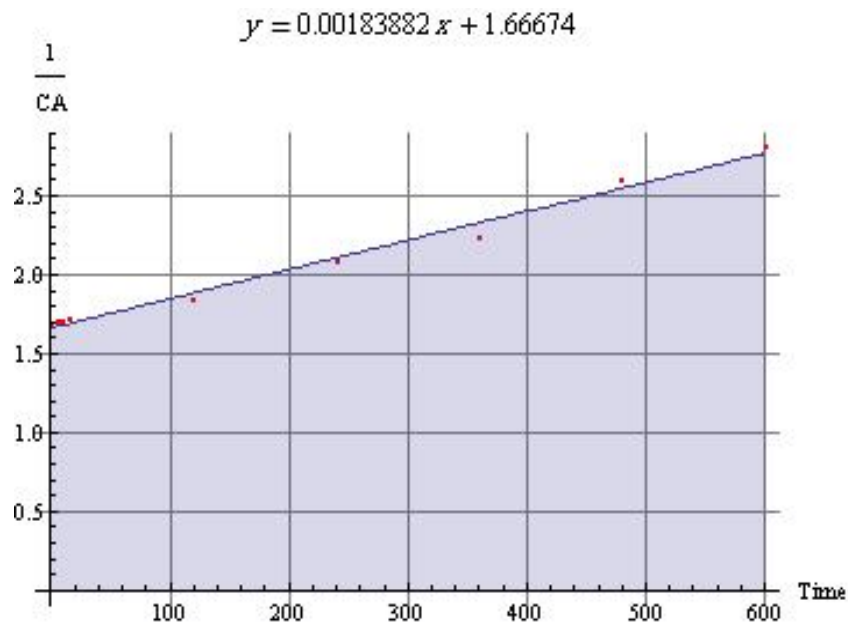

Figure 2: Representation of the hexamine dinitrate concentration-time data at $15^{\circ} \mathrm{C}$ - Second Order, $\mathrm{R}^{2}=0.994147$.

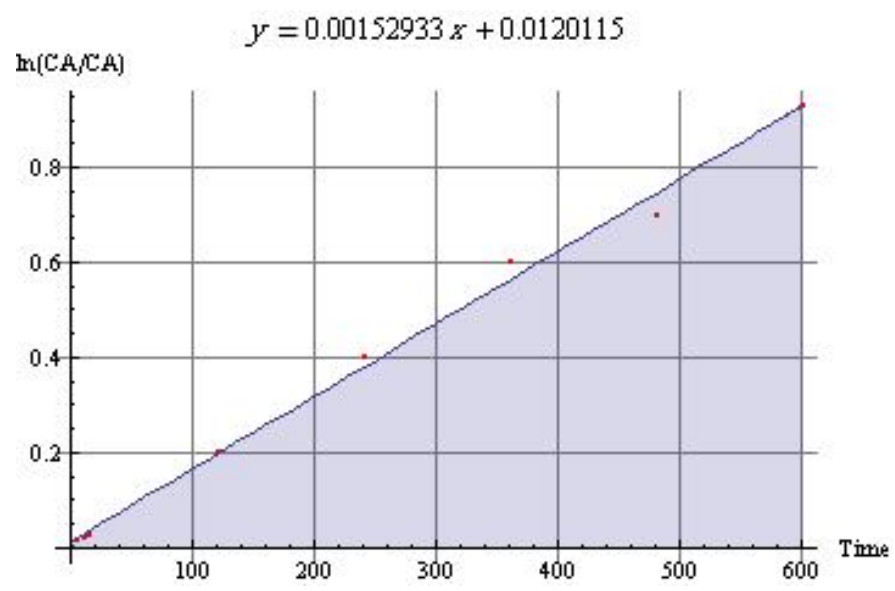

Figure 3: Representation of the hexamine dinitrate concentration-time data at $25^{\circ} \mathrm{C}$ - First Order, $\mathrm{R}^{2}=0.997851$.

Similarly, The rate of conversion of hexamine dinitrate into DPT at $25^{\circ} \mathrm{C}$ was found relatively higher than that at $15^{\circ} \mathrm{C}$. Depletion of about $60 \%$ of hexamine dinitrate was achieved after 600 minutes as shown in Table 2.

Table 2: DPT and hexamine dinitrate concentrations and concentration terms at different reaction times at $25^{\circ} \mathrm{C}$.

\begin{tabular}{c|ccccccccc}
\hline $\begin{array}{c}\text { Time } \\
(\mathrm{min} .)\end{array}$ & 0 & 5 & 10 & 15 & 120 & 240 & 360 & 480 & 600 \\
\hline $\begin{array}{c}\text { Hexamine } \\
\text { dinitrate } \\
(\mathrm{mg} / \mathrm{ml})\end{array}$ & 0.597 & 0.586 & 0.585 & 0.581 & 0.488 & 0.400 & 0.327 & 0.296 & 0.235 \\
\hline
\end{tabular}


M. H. El Dewaik et al., International Journal of Advanced Trends in Computer Science and Engineering, 9(4), July - August 2020, 6774 - 6782

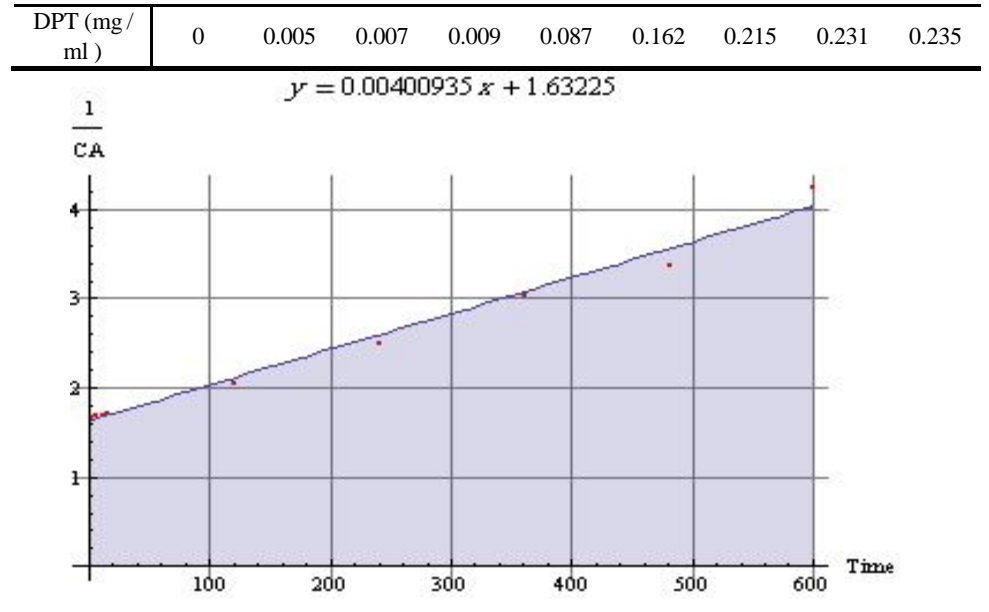

Figure 4: Representation of the hexamine dinitrate concentration-time data at $25^{\circ} \mathrm{C}$ - Second Order, $\mathrm{R}^{2}=0.992881$.

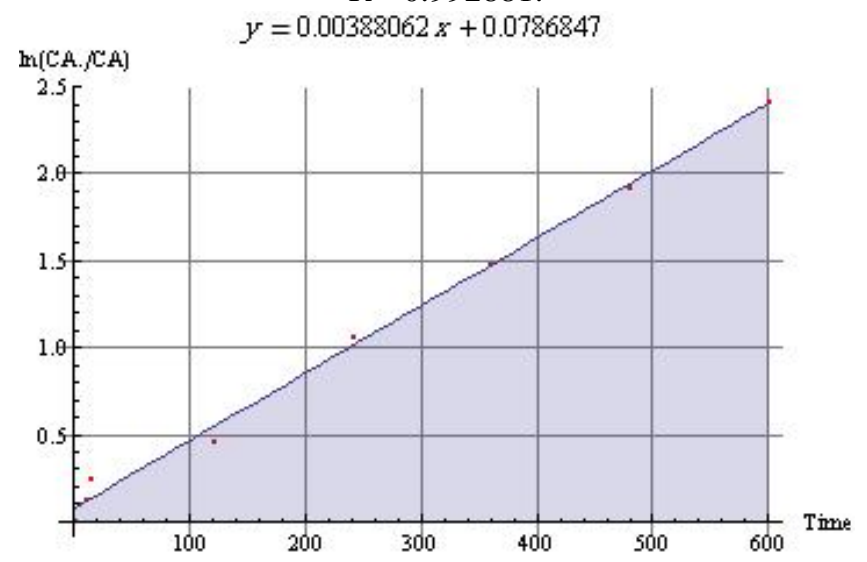

Figure 5: Representation of the hexamine dinitrate concentration-time data at $35^{\circ} \mathrm{C}$ - First Order, $\mathrm{R}^{2}=0.99773$. The reaction rate was appreciably higher than that found below this temperature. About $90 \%$ conversion was recorded after 600 minutes.

Table 3: DPT and hexamine dinitrate concentrations and concentration terms at different reaction times at $35^{\circ} \mathrm{C}$

\begin{tabular}{c|ccccccccc}
\hline $\begin{array}{c}\text { Time } \\
\text { (min.) }\end{array}$ & 0 & 5 & 10 & 15 & 120 & 240 & 360 & 480 & 600 \\
\hline $\begin{array}{c}\text { Hexamine } \\
\text { dinitrate } \\
(\mathrm{mg} / \mathrm{ml})\end{array}$ & 0.588 & 0.532 & 0.521 & 0.458 & 0.369 & 0.202 & 0.134 & 0.086 & 0.052 \\
\hline $\begin{array}{c}\text { DPT (mg/ } \\
\mathrm{ml})\end{array}$ & 0 & 0.034 & 0.050 & 0.102 & 0.178 & 0.315 & 0.368 & 0.401 & 0.438 \\
\hline
\end{tabular}

Decomposition of hexamine dinitrate became faster than that found below this temperature. About two thirds of the hexamine dinitrate were depleted during the first fifteen minutes. This temperature has been already recommended by many authors

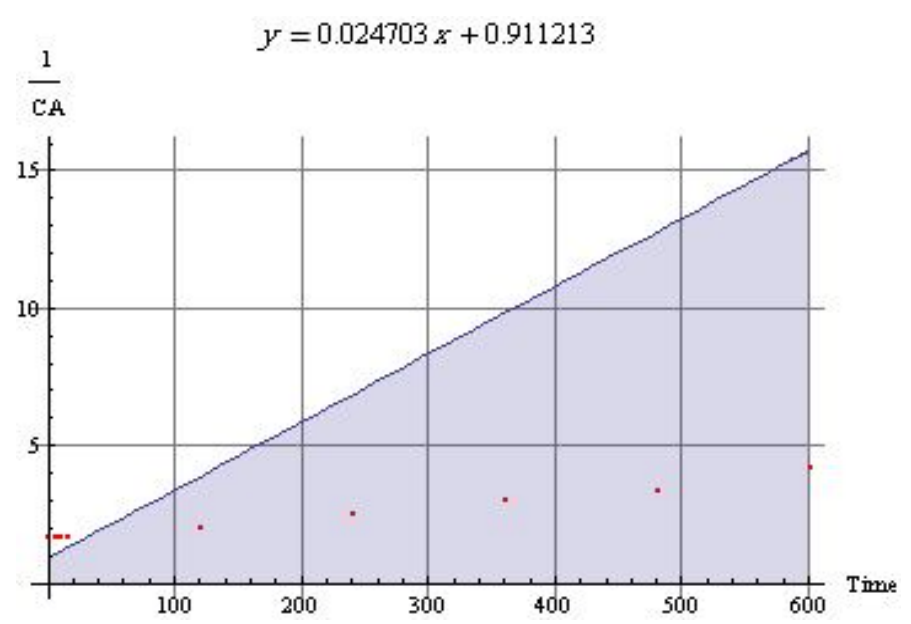

Figure 6: Representation of the hexamine dinitrate concentration-time data at $35{ }^{\circ} \mathrm{C}$ - Second Order, $\mathrm{R}^{2}=0.953836$

Table 4: DPT and hexamine dinitrate concentrations and concentration terms at different reaction times at $45^{\circ} \mathrm{C}$

\begin{tabular}{c|cccccccccc}
\hline $\begin{array}{c}\text { Time } \\
\text { (min.) }\end{array}$ & 0 & 1 & 2 & 3 & 5 & 6 & 8 & 10 & 12 & 15 \\
\hline $\begin{array}{c}\text { Hexamine } \\
\text { dinitrate } \\
(\mathrm{mg} / \mathrm{ml})\end{array}$ & 0.59 & 0.56 & 0.54 & 0.52 & 0.44 & 0.40 & 0.35 & 0.33 & 0.28 & 0.20 \\
\hline $\begin{array}{c}\text { DPT }(\mathrm{mg} / \\
\mathrm{ml})\end{array}$ & 0 & 0.02 & 0.03 & 0.05 & 0.12 & 0.14 & 0.19 & 0.20 & 0.25 & 0.32 \\
\hline
\end{tabular}

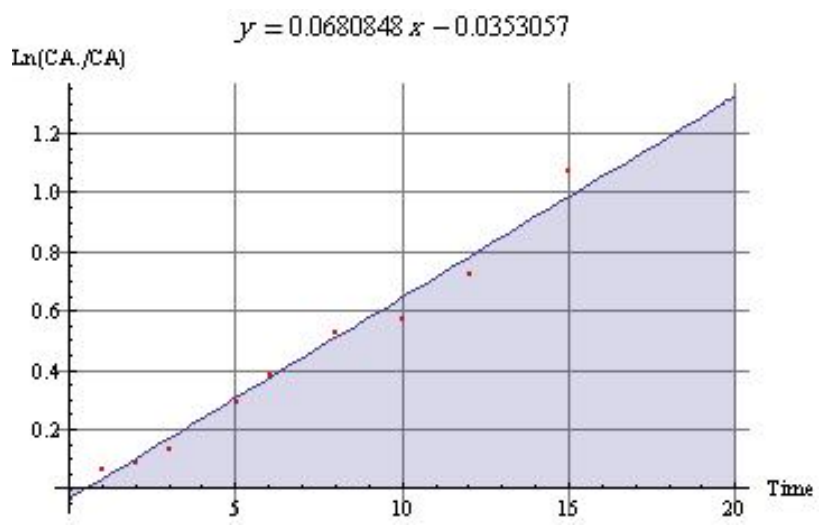

Figure 7: Representation of the hexamine dinitrate concentration-time data at $45^{\circ} \mathrm{C}$ - First Order, $\mathrm{R}^{2}=0.990814$.

The concentrations and concentration terms found at $55{ }^{\circ} \mathrm{C}$ were neither fitting tightly to the first order nor to the second order ordinary kinetic models. The reaction at this temperature was faster. About $74 \%$ of the hexamine dinitrate were depleted during the first fifteen minutes. The formed DPT was somewhat less than the theoretical. This may be attributed to some sort of the side reactions. This 
M. H. El Dewaik et al., International Journal of Advanced Trends in Computer Science and Engineering, 9(4), July - August 2020, $6774-6782$

may also explain the recommendation given by many authors which limit the reaction temperature to $45^{\circ} \mathrm{C}$.

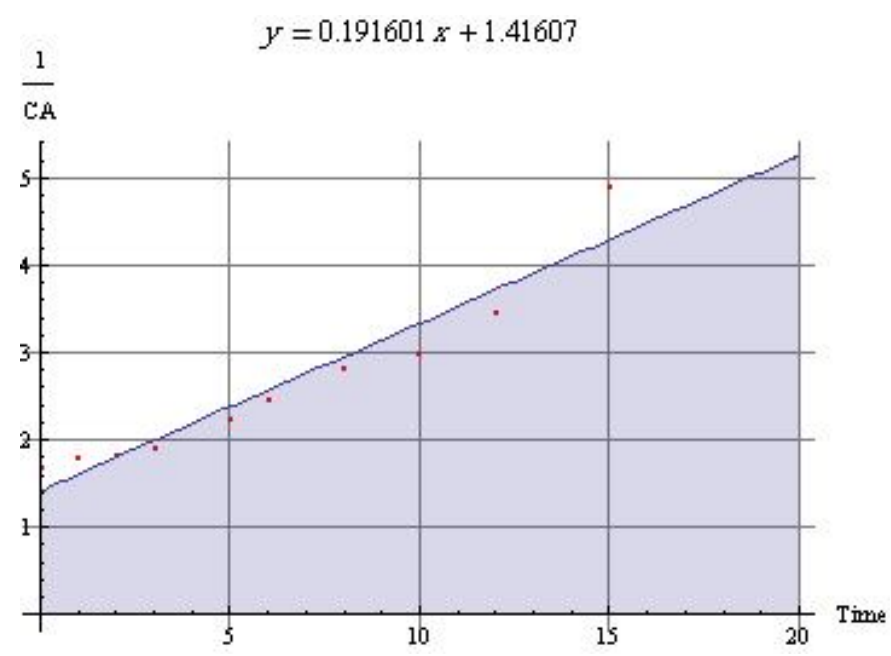

Figure 8: Representation of the hexamine dinitrate concentration-time data at $45{ }^{\circ} \mathrm{C}-$ Second Order, $\mathrm{R}^{2}=0.960295$.

Table 5: DPT and hexamine dinitrate concentrations and concentration terms at different reaction times at $55^{\circ} \mathrm{C}$

\begin{tabular}{c|cccc}
\hline Time (min.) & 0 & 5 & 10 & 15 \\
\hline Hexamine dinitrate $(\mathrm{mg} / \mathrm{ml})$ & 0.5969 & 0.4082 & 0.3254 & 0.1552 \\
& 8 & 5 & 0 & 2 \\
\hline DPT $(\mathrm{mg} / \mathrm{ml})$ & 0 & 0.1340 & 0.1875 & 0.2764 \\
& & 0 & 0 & 0 \\
\hline
\end{tabular}

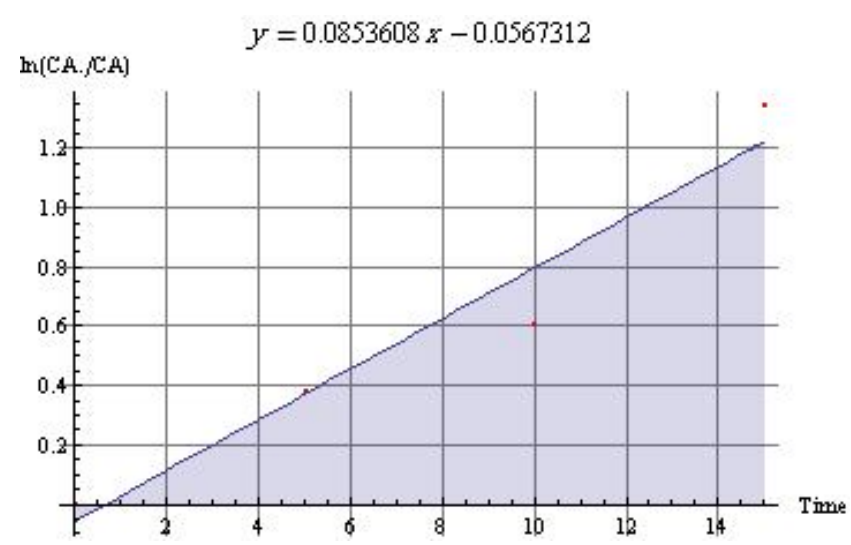

Figure 9: Representation of the hexamine dinitrate concentration-time data at $55^{\circ} \mathrm{C}$ - First Order, $\mathrm{R}^{2}=0.97128$.

The concentrations and concentration terms found at $65{ }^{\circ} \mathrm{C}$ were neither fitting tightly to the first order nor to the second order ordinary kinetic models. The reaction was as usual faster. About $77 \%$ of the hexamine dinitrate were depleted in the first fifteen minutes. The DPT yield was less than that found in the literature.

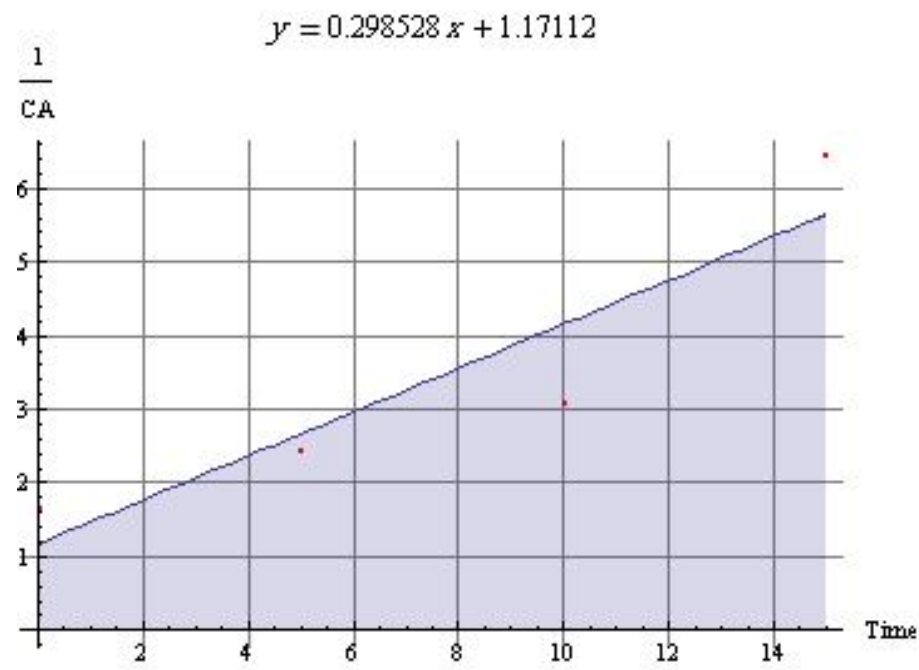

Figure 10: Representation of the hexamine dinitrate concentration-time data at $55^{\circ} \mathrm{C}$ - Second Order, $\mathrm{R}^{2}=0.917158$.

Table 6: DPT and hexamine dinitrate concentrations and concentration terms at different reaction times at $65^{\circ} \mathrm{C}$

\begin{tabular}{c|cccc}
\hline Time (min.) & 0 & 5 & 10 & 15 \\
\hline Hexamine dinitrate $(\mathrm{mg} / \mathrm{ml})$ & $\mathbf{0 . 5 9 7 8 0}$ & $\mathbf{0 . 3 9 8 5 0}$ & $\mathbf{0 . 2 8 3 7 0}$ & $\mathbf{0 . 1 4 0 4 8}$ \\
\hline DPT $(\mathrm{mg} / \mathrm{ml})$ & $\mathbf{0}$ & $\mathbf{0 . 1 4 2 0 0}$ & $\mathbf{0 . 1 9 2 3 0}$ & $\mathbf{0 . 2 6 2 3 5}$ \\
\hline
\end{tabular}

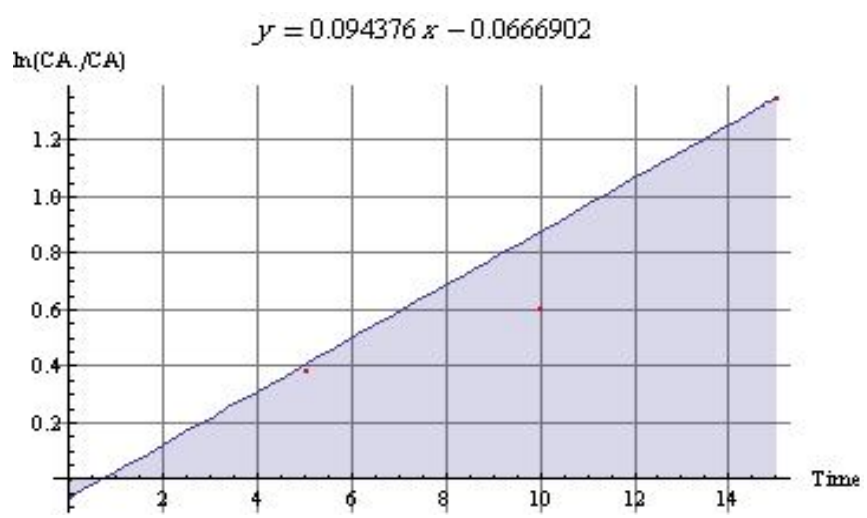

Figure 11: Representation of the hexamine dinitrate concentration-time data at $65^{\circ} \mathrm{C}$ - First Order, $\mathrm{R}^{2}=0.988583$. 


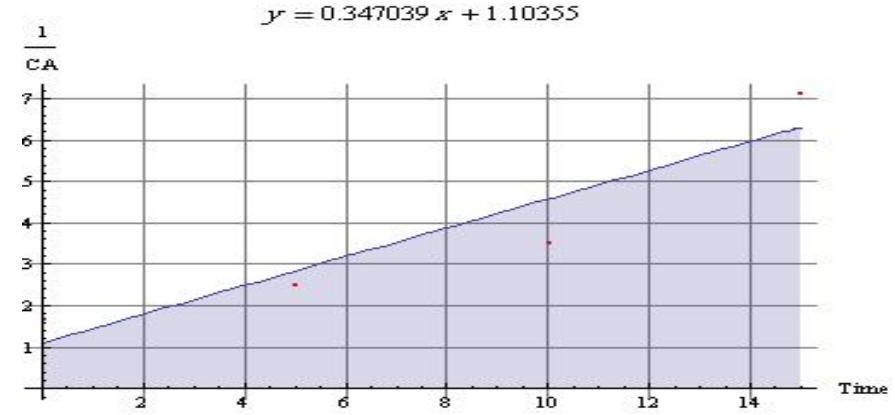

Figure 12: Representation of the hexamine dinitrate concentration-time data at $55{ }^{\circ} \mathrm{C}$ - Second Order, $\mathrm{R}^{2}=0.934405$.

Table 7: Determined values of reaction rate constant of hexamine dinitrate conversion into DPT at different temperatures for the first and second order kinetic model.

\begin{tabular}{|c|c|c|c|c|}
\hline $\begin{array}{c}\text { Temperatur } \\
\mathrm{e}\end{array}$ & \multicolumn{2}{|c|}{ Rate Constant(k) } & \multicolumn{2}{|c|}{$\begin{array}{l}\text { Correlation } \\
\text { Factor }\left(\mathrm{R}^{2}\right)\end{array}$} \\
\hline$\left({ }^{\circ} \mathrm{C}\right)$ & $\begin{array}{c}1-\mathrm{st} \\
\operatorname{order}\left(\mathrm{s}^{-1}\right)\end{array}$ & $\begin{array}{c}\text { 2-nd order } \\
\left(\mathrm{L} \cdot \mathrm{mol}^{-1} \cdot \mathrm{sec}^{-1}\right)\end{array}$ & $\begin{array}{l}1-\text {-st } \\
\text { order }\end{array}$ & $\begin{array}{l}2 \text {-nd } \\
\text { order }\end{array}$ \\
\hline 15 & 0.0009 & 0.0018 & 0.9956 & 0.9883 \\
\hline 25 & 0.0016 & 0.004 & 0.995 & 0.9858 \\
\hline 35 & 0.0041 & 0.0247 & 0.9908 & 0.9098 \\
\hline 45 & 0.0645 & 0.1915 & 0.9773 & 0.9222 \\
\hline 55 & 0.0805 & 0.2985 & 0.9386 & 0.8412 \\
\hline 65 & 0.0887 & 0.347 & 0.9658 & 0.8731 \\
\hline
\end{tabular}

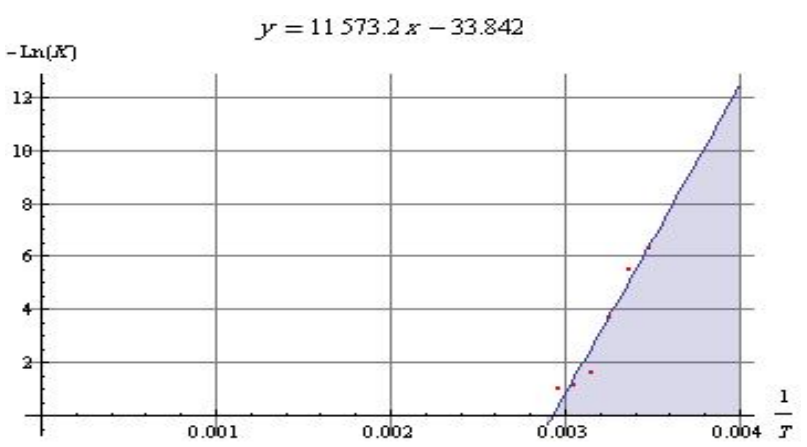

At each temperature, the analysis was done at different reaction times. The above mentioned figure shows the chromatogram obtained at the end of the investigated reaction time at $45^{\circ} \mathrm{C}$. By examining the obtained chromatograms, the prepared compounds were identified and quantified. Concentrations of both unreacted and formed species were determined, where $C_{A}$. and $C_{A}$ are the initial and final concentrations of hexamine dinitrate respectively. The complete data and calculated results of HPLC analysis are summarized in previously mentioned Tables. As a first approximation, the reaction may be treated as a homogeneous one. From the concentration results, namely $\ln \left(\mathrm{CA} / \mathrm{C}_{\mathrm{A}}\right)$ and $\left(1 / \mathrm{C}_{\mathrm{A}}\right)$, shown above, the rate constant was calculated for first and second order kinetic models respectively as shown in the following Figures 13 and 14. The obtained values of rate constant are summarized in Table 7.

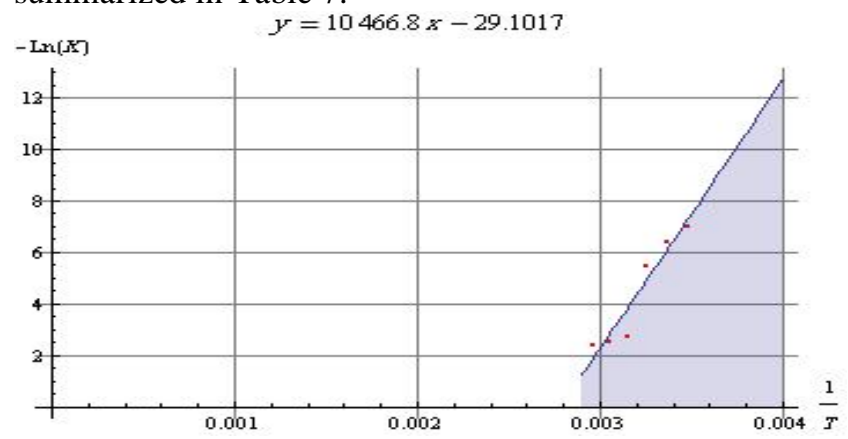

Figure 13: Representation of the hexamine dinitrate concentration - time data at $45^{\circ} \mathrm{C}$, according to first order kinetic models.

Similarly, Mathematica is used to obtain more accurate and optimized results. The arte constant is simply calculated from the obtained concentration results as shown in Figure 13-14 based on the calculated results from Table 7. [45]

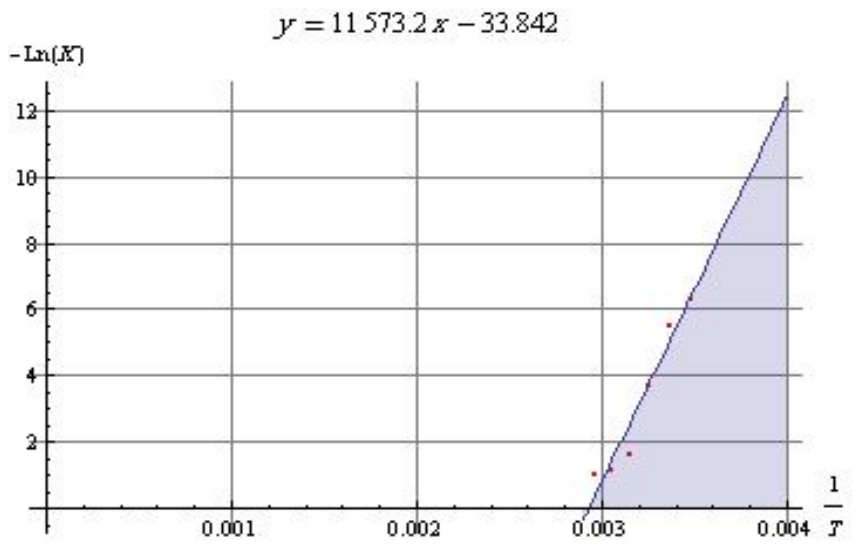

Figure 14: Representation of the hexamine dinitrate concentration - time data at $45^{\circ} \mathrm{C}$, according to second order kinetic models.

From Table 7, it is clear that the calculated rate constant, according to the first order model, is nearly doubled for each decade of temperature rise up to $35^{\circ} \mathrm{C}$. However, at $45^{\circ} \mathrm{C}$ the rate constant increases almost sixteen times.

Further increase of temperature, nearly $55^{\circ} \mathrm{C}$ and $65^{\circ} \mathrm{C}$, has a slight effect on the rate constant. The results confirm the reported data in literature [11] that the optimal reaction temperature is $45^{\circ} \mathrm{C}$. On the other hand, for the second order kinetic model, the increase of the rate constant with temperature is irregular and unjustifiable, especially at low temperatures. Moreover, the correlation factor values for the second order are inferior to those obtained for first order kinetic model. Arrhenius equation was used to calculate the activation energy of the reaction under investigation. The relation between $\ln (\mathrm{k})$ and $(1 / \mathrm{T})$ for both first and second order kinetic model is shown in Figures 13-14.

The activation energy of the reaction was investigated using Arrhenius equation. The proposed kinetic model was found to be second order kinetic model based on the experimental data that were processed in order to find a relation between $\ln (\mathrm{k})$ and $(1 / \mathrm{T})$ as shown in Figure 13-14. 
The data in Table 7 are linearly interpolated with Mathematica 10 to get a relation between the slopes k of the reactions with the temperature, and the data with the corresponding line are plotted in figure 13-14.

\section{CONCLUSION}

In conclusion, Mathematica was used as a powerful program for computing both numeric and algebraic calculations in many fields of science now such as physics, engineering, chemistry and even biology. Mathematica is one of the most powerful tools for dealing with data nowadays. It is used with any kind of data regardless of its nature whether biological, chemical or engineering data. Mathematica arrange and summarize the data. It also describe it by interpolating for best possible curves and then any kinds of graphs can be achieved. Also after the process of summarizing and interpolation. It is straight forward calculations to get the required statistical parameters of the data and also to measure the strength of interaction between different sets of data

We report here, optimizing the kinetic data DPT via using Mathematica. It was determined that the order of the reaction is a second-order reaction. The work reports the synthesis of DPT as an important and key intermediate for the synthesis of RDX and HMX. Recently, new research efforts have been devoted to increase the performance of energetic materials using nanocomposites and nanoparticles due to its unique properties not only in the field of energetic materials but also in other applications including medical, environmental, and industrial applications. [16-41]

The yield of the DPT prepared was about $65 \%$; while the yield of the hexamine dinitrate prepared was about $89 \%$. The analysis of the prepared samples using an efficient HPLC was a very reliable procedure. Decomposition of hexamine dinitrate became faster than that found below this temperature. About two thirds of the hexamine dinitrate were depleted during the first fifeteen minutes. This temperature has been already recommended by many authors. The temperature of $45 \pm 2{ }^{\circ} \mathrm{C}$ is the optimum temperature that gives the optimum conversion and yield. The analysis of the prepared samples using an efficient HPLC was a very reliable procedure. The concentrations and concentration terms found at $45^{\circ} \mathrm{C}$ were not fitting tightly to the ordinary second order kinetic model. Decomposition of hexamine dinitrate became faster and faster than that found below this temperature. About two thirds of the hexamine dinitrate were depleted during the first fifteen minutes. This temperature has been already recommended by many authors $[6,10]$. The applicability of the first order model which gave higher correlation coefficient when compared with the second.

\section{ACKNOWLEDGEMENT}

We express our deep gratitude to British University in Egypt (BUE). This work was partially performed using the facilities at the Nanotechnology Research Centre (NTRC) at the British University in Egypt (BUE). The authors express their deep gratitude for the financial support of the research project entitled "Synthesis and kinetic study of a selected energetic material" that has been provided by The Military Technical College, Cairo, Egypt.

The authors also thank Prof. M. M. Seleet and Prof. Said M. A. Hassanein for their kind help, guidance, and support during all steps of this work, The School of Chemical Engineering at Military Technical College for using their facilities, and we also thank Prof. Shoukry M. Fayed, Prof. Omar Al-Farouk and Prof. Ahmed Baraka for their kind and valuable scientific comments and support which enabled us to finish this work.

\section{REFERENCES}

1. Chen S.T., Synthesis of Pd/Fe3O4 Hybrid Nanocatalysts with Controllable Interface and Enhanced Catalytic Activities for CO Oxidation, Journal of Physical Chemistry C, Vol. 116, pp. 2969-12976, March 2012.

2. Radwan N.R.E., El-Shall M.S., Hassan H.M.A., Synthesis and characterization of nanoparticle $\mathrm{Co3O4}, \mathrm{CuO}$ and $\mathrm{NiO}$ catalysts prepared by physical and chemical methods to minimize air pollution, Applied Catalysis A: General, Vol. 331, pp. 8-18, August 2007.

3. Wang H.L., $\mathbf{N i ( O H ) ( 2 ) ~ N a n o p l a t e s ~ G r o w n ~ o n ~}$ Graphene as Advanced Electrochemical Pseudocapacitor Materials, Journal of the American Chemical Society, Vol. 132, 21, pp. 7472-7477, February 2010.

4. Wang W.W., Zhu Y.J., Ruan M.L., Microwave-assisted synthesis and magnetic property of magnetite and hematite nanoparticles, Journal of Nanoparticle Research, Vol. 9, 3, pp. 419-426, April 2007.

5. Elazab H., Microwave-assisted synthesis of Pd nanoparticles supported on $\mathrm{FeO}, \mathrm{CoO}$, and $\mathrm{Ni}(\mathrm{OH})$ nanoplates and catalysis application for $\mathrm{CO}$ oxidation, Journal of Nanoparticle Research, Vol. 16, 7, pp. 1-11, November 2014.

6. Mankarious R.A., et al., Bulletproof vests/shields prepared from composite material based on strong polyamide fibers and epoxy resin, Journal of Engineering and Applied Sciences, Vol. 12, 10, pp. 2697-2701, May 2017.

7. Mohsen W., Sadek M.A., Elazab H.A., Green synthesis of copper oxide nanoparticles in aqueous medium as a potential efficient catalyst for catalysis applications, International Journal of Applied Engineering Research, Vol. 12, 24, pp. 14927-14930, July 2017.

8. Mostafa A.R., Omar H.A.-S., Hany A.E., Preparation of Hydrogel Based on Acryl Amide and Investigation of Different Factors Affecting Rate and Amount of 
Absorbed Water, Agricultural Sciences, Vol. 8, pp. 2-11, June 2017.

9. Radwan M.A., et al., Mechanical characteristics for different composite materials based on commercial epoxy resins and different fillers, Journal of Engineering and Applied Sciences, Vol. 12, 5, pp. 1179-1185, May 2017.

10. Andrade A.L., Catalytic Effect of Magnetic Nanoparticles Over the $\mathrm{H}(2) \mathrm{O}(2)$ Decomposition Reaction, Journal of Nanoscience and Nanotechnology, Vol. 9, 6, pp. 3695-3699, June 2009.

11. Kustov A.L., CO methanation over supported bimetallic Ni-Fe catalysts: From computational studies towards catalyst optimization, Applied Catalysis a-General, Vol. 320, pp. 98-104, November 2007.

12. Lohitharn N., Goodwin J.G., Impact of $\mathbf{C r}, \mathbf{M n}$ and $\mathbf{Z r}$ addition on Fe Fischer-Tropsch synthesis catalysis: Investigation at the active site level using SSITKA, Journal of Catalysis, Vol. 257, 1, pp. 142-151, August 2008.

13. Moreau F., Bond G.C., CO oxidation activity of gold catalysts supported on various oxides and their improvement by inclusion of an iron component, Catalysis Today, Vol. 114, 4, pp. 362-368, October 2006.

14. Sarkari M., Fischer-Tropsch synthesis: Development of kinetic expression for a sol-gel $\mathrm{Fe}-\mathrm{Ni} / \mathrm{Al2O3}$ catalyst, Fuel Processing Technology, Vol. 97, pp. 130-139, April 2012.

15. Elazab H., The Effect of Graphene on Catalytic Performance of Palladium Nanoparticles Decorated with $\mathrm{FeO}$, $\mathrm{CoO}$, and $\mathrm{Ni}(\mathrm{OH})$ : Potential Efficient Catalysts Used for Suzuki Cross-Coupling, Catalysis Letters, Vol. 147, 6, pp. 1510-1522, July 2017.

16. Elazab H.A., The continuous synthesis of Pd supported on $\mathrm{Fe} 3 \mathrm{O} 4$ nanoparticles: A highly effective and magnetic catalyst for $\mathrm{CO}$ oxidation, Green Processing and Synthesis, Vol. 6, 4, pp. 413-424, May 2017.

17. Elazab H.A., Sadek M.A., El-Idreesy T.T., Microwave-assisted synthesis of palladium nanoparticles supported on copper oxide in aqueous medium as an efficient catalyst for Suzuki cross-coupling reaction, Adsorption Science \& Technology, Vol. 36, pp. 1352-1365, May 2018.

18. Elazab H.A., Highly efficient and magnetically recyclable graphene-supported $\mathrm{Pd} / \mathrm{Fe3O4}$ nanoparticle catalysts for Suzuki and Heck cross-coupling reactions, Applied Catalysis A: General, Vol. 491, pp. 58-69, February 2015.

19. Hirvi J.T., et al., CO oxidation on PdO surfaces, Journal of Chemical Physics, Vol. 133, pp. 8-14, August 2010.

20. Iglesias-Juez A., Nanoparticulate Pd Supported Catalysts: Size-Dependent Formation of $\operatorname{Pd}(\mathbf{I}) / \operatorname{Pd}(0)$ and Their Role in CO Elimination, Journal of the American Chemical Society, Vol. 133, 12, pp. 4484-4489, March 2011
21. Ivanova A.S., Metal-support interactions in Pt/Al2O3 and $\mathrm{Pd} / \mathrm{Al} 2 \mathrm{O3}$ catalysts for $\mathrm{CO}$ oxidation, Applied Catalysis B-Environmental, Vol. 97, 1-2, pp. 57-71, April 2010.

22. Kim H.Y., Henkelman G., CO Oxidation at the Interface between Doped $\mathrm{CeO} 2$ and Supported Au Nanoclusters, Journal of Physical Chemistry Letters, Vol. 3, 16, pp. 2194-2199, January 2012.

23. Chattopadhyay K., Dey R., Ranu B.C., Shape-dependent catalytic activity of copper oxide-supported $\operatorname{Pd}(0)$ nanoparticles for Suzuki and cyanation reactions, Tetrahedron Letters: International Organ for the Rapid Publication of Preliminary Communications in Organic Chemistry, Vol. 50, 26. pp. 3164-3167, December 2009.

24. Hoseini S.J., Modification of palladium-copper thin film by reduced graphene oxide or platinum as catalyst for Suzuki-Miyaura reactions, Applied Organometallic Chemistry, Vol. 31, pp. 5-12, March 2017.

25. Hosseini-Sarvari M., Razmi Z., Palladium Supported on Zinc Oxide Nanoparticles as Efficient Heterogeneous Catalyst for Suzuki Miyaura and Hiyama Reactions under Normal Laboratory Conditions, Helvetica Chimica Acta, Vol. 98, 6, pp. 805-818, April 2015.

26. Nasrollahzadeh M., Ehsani A., Jaleh B., Preparation of carbon supported CuPd nanoparticles as novel heterogeneous catalysts for the reduction of nitroarenes and the phosphine-free Suzuki Miyaura coupling reaction, New Journal of Chemistry, Vol. 39, 2, pp. 1148-1153, February 2015.

27. Nasrollahzadeh M., Palladium nanoparticles supported on copper oxide as an efficient and recyclable catalyst for carbon(sp2) carbon(sp2) cross-coupling reaction, Materials Research Bulletin, Vol. 68, pp. 150-154, April 2013.

28. Mandali P.K., Chand D.K., Palladium nanoparticles catalyzed Suzuki cross-coupling reactions in ambient conditions, Catalysis Communications, Vol. 31, pp.16-20, November 2016.

29. Wang Y., CuO Nanorods-Decorated Reduced Graphene Oxide Nanocatalysts for Catalytic Oxidation of CO, Catalysts, Vol. 6, 12, pp. 214-220, September 2016

30. Igarashi H., Uchida H., Watanabe M., Mordenite-supported noble metal catalysts for selective oxidation of carbon monoxide in a reformed gas, Chemistry Letters, Vol. 11, pp. 1262-1263, October 2000.

31. Liu W.H., Fleming S., Lairson B.M., Reduced intergranular magnetic coupling in $\mathbf{P d} / \mathbf{C o}$ multilayers, Journal of Applied Physics, Vol. 79, 7, pp. 3651-3655, May 1996.

32. Luo J.Y., Mesoporous $\operatorname{Co}(3) \mathrm{O}(4)-\mathrm{CeO}(2)$ and $\mathrm{Pd} / \mathrm{Co}(3) \mathrm{O}(4)-\mathrm{CeO}(2) \quad$ catalysts: Synthesis, characterization and mechanistic study of their 
catalytic properties for low-temperature CO oxidation, Journal of Catalysis, Vol. 254, 2, pp. 310-324, June 2008.

33. Pavlova S.N., The influence of support on the low-temperature activity of $\mathrm{Pd}$ in the reaction of $\mathrm{CO}$ oxidation on Kinetics and mechanism of the reaction, Journal of Catalysis, Vol. 161, 2, pp. 517-523, May 1996.

34. Diyarbakir S.M., Can H., Metin Ã.n., Reduced Graphene Oxide-Supported CuPd Alloy Nanoparticles as Efficient Catalysts for the Sonogashira Cross-Coupling Reactions, Acs Applied Materials \& Interfaces, Vol. 7, 5, pp. 3199-3206, March 2015.

35. Feng Y.-S., et al., ChemInform Abstract: PdCu Nanoparticles Supported on Graphene: An Efficient and Recyclable Catalyst for Reduction of Nitroarenes, ChemInform, Vol. 46, pp. 4-12, August 2015.

36. Feng Y.-S., et al., PdCu nanoparticles supported on graphene: an efficient and recyclable catalyst for reduction of nitroarenes, Tetrahedron, Vol. 70, 36, pp. 6100-6105, May 2014.

37. Liu Y., et al., Ultrasensitive electrochemical immunosensor for SCCA detection based on ternary $\mathrm{Pt} / \mathrm{PdCu}$ nanocube anchored on three-dimensional graphene framework for signal amplification, Biosensors \& Bioelectronics, Vol. 79, pp. 71-78, July 2016.

38. Shafaei Douk A., Saravani H., Noroozifar M., Novel fabrication of $\mathrm{PdCu}$ nanostructures decorated on graphene as excellent electrocatalyst toward ethanol oxidation, International Journal of Hydrogen Energy, Vol. 42, 22, pp. 15149-15159, August 2017.

39. Hany A. Elazab, Investigation of Microwave-assisted Synthesis of Palladium Nanoparticles Supported on $\mathrm{Fe}_{3} \mathrm{O}_{4}$ as an Efficient Recyclable Magnetic Catalysts for Suzuki Cross - Coupling, The Canadian Journal of Chemical Engineering, Vol. 96, 12, pp. 250-261, January 2019.

40. Hany A. Elazab, Laser Vaporization and Controlled Condensation (LVCC) of Graphene supported $\mathrm{Pd} / \mathrm{Fe}_{3} \mathrm{O}_{4}$ Nanoparticles as an Efficient Magnetic Catalysts for Suzuki Cross - Coupling, Biointerface Research in Applied Chemistry, Vol. 8, 3, pp. 3314 3318, August 2018.

41. Hany A. Elazab, The catalytic Activity of Copper Oxide Nanoparticles towards Carbon Monoxide Oxidation Catalysis: Microwave - Assisted Synthesis Approach, Biointerface Research in Applied Chemistry, Vol. 8, 3, pp. 3278 - 3281, June 2018.

42. M. A. Radwan, Omar Al-Sweasy, M. A. Sadek, Hany A. Elazab, Investigating the Agricultural Applications of Acryl Amide based Hydrogel, International Journal of Engineering and Technology(UAE), Vol. 7, 4.29, pp. 168-171, April 2018.
43. Fatma Zakaria, M. A. Radwan, M. A. Sadek, Hany A. Elazab, Insulating material based on shredded used tires and inexpensive polymers for different roofs, International Journal of Engineering and Technology(UAE), Vol. 7, 4, pp. 1983-1988, June 2018.

44. Reem Nasser, M. A. Radwan, M. A. Sadek, Hany A. Elazab, Preparation of insulating material based on rice straw and inexpensive polymers for different roofs, International Journal of Engineering and Technology(UAE), Vol. 7, 4, pp. 1989-1994, June 2018.

45. Mostafa Ghobashy, Mamdouh Gadallah, Tamer T. El-Idreesy, M. A. Sadek, Hany A. Elazab, Kinetic Study of Hydrolysis of Ethyl Acetate using Caustic Soda, International Journal of Engineering and Technology(UAE), Vol. 7, 4, pp. 1995-1999, June 2018.

46. Nourhan Sherif Samir, Mostafa A. Radwan, M. A. Sadek, Hany A. Elazab, Preparation and Characterization of Bullet-Proof Vests Based on Polyamide Fibers, International Journal of Engineering and Technology(UAE), Vol. 7, 3, pp. 1290-1294, May 2018.

47. Basant Ashraf, Mostafa A. Radwan, M. A. Sadek, Hany A. Elazab, Preparation and Characterization of Decorative and Heat Insulating Floor Tiles for Buildings Roofs, International Journal of Engineering and Technology (UAE), Vol. 7, 3, pp. 1295-1298, May 2018.

48. Mandali P.K., Chand D.K., Palladium nanoparticles catalyzed Suzuki cross-coupling reactions in ambient conditions, Catalysis Communications, Vol. 31, 5, pp. 16-20, October 2016.

49. Wang Y., CuO Nanorods-Decorated Reduced Graphene Oxide Nanocatalysts for Catalytic Oxidation of CO, Catalysts, Vol. 6, 12, pp. 214-223, April 2016.

50. Pavlova S.N., The influence of support on the low-temperature activity of $\mathrm{Pd}$ in the reaction of $\mathrm{CO}$ oxidation on Kinetics and mechanism of the reaction, Journal of Catalysis, Vol. 161, 2, pp. 517-523, July 1996.

51. Diyarbakir S.M., Can H., Metin Ã.n., Reduced Graphene Oxide-Supported CuPd Alloy Nanoparticles as Efficient Catalysts for the Sonogashira Cross-Coupling Reactions, Acs Applied Materials \& Interfaces, Vol. 7, 5, pp. 3199-3206, June 2015.

52. M. A. Radwan, Mohamed Adel Rashad, M. A. Sadek, Hany A. Elazab, Synthesis, Characterization and Selected Application of Chitosan Coated Magnetic Iron Oxide Nanoparticles, Journal of Chemical Technology and Metallurgy, Vol. 54, 2, pp. 303-310, June 2019.

53. Hosam H. Abdelhady, Hany A. Elazab, Emad M. Ewais, Mohamed Saber, Mohamed S. El-Deab, Efficient Catalytic Production of Biodiesel Using Nano-Sized Sugarbeet Agro-Industrial waste, Fuel, Vol. 261, pp. 116481, February 2020.

54. Hany A. Elazab, M. A. Sadek, Tamer T. El-Idreesy, Facile Synthesis of Reduced Graphene 
Oxide-Supported Pd/CuO Nanoparticles as an Efficient Catalyst for Cross-Coupling Reactions, Journal of Chemical Technology and Metallurgy, Vol. 54, 5, pp. 934-946, August 2019.

55. Hany A. Elazab, Tamer T. El-Idreesy, Polyvinylpyrrolidone - Reduced Graphene Oxide - Pd Nanoparticles as an Efficient Nanocomposite for Catalysis Applications in Cross-Coupling Reactions, Bulletin of Chemical Reaction Engineering and Catalysis, Vol. 14, 3, pp. 490-501, December 2019.

56. Hany A. Elazab, Ali R. Siamaki, B. Frank Gupton, M. Samy El-Shall, Pd-Fe $\mathrm{O}_{\mathbf{4}} / \mathbf{R G O}$ : a Highly Active and Magnetically Recyclable Catalyst for Suzuki Cross Coupling Reaction using a Microfluidic Flow Reactor, Bulletin of Chemical Reaction Engineering and Catalysis, Vol. 14, 3, pp. 478-489, December 2019.

57. Hany A. Elazab, M. A. Radwan, Tamer T. El-Idreesy, Facile microwave-assisted synthetic approach to palladium nanoparticles supported on copper oxide as an efficient catalyst for Heck cross-coupling reactions, International Journal of Nanoscience, Vol. 18, 5, pp. 1850032, June 2019.

58. Hany A. Elazab, S. A. Hassan, M. A. Radwan, M. A. Sadek, Microwave-assisted Synthesis of Graphene supported Hexagonal Magnetite for Applications in Catalysis, International Journal of Innovative Technology and Exploring Engineering (IJITEE), Vol. 8, 12, 5511-5513, 2019.

59. Hany A. Elazab, M. A. Radwan, M. A. Sadek, Hydrothermal Synthesis of Palladium nanoparticles supported on $\mathrm{Fe}_{3} \mathrm{O}_{4}$ Nanoparticles: an Efficient Magnetic Catalysts for CO Oxidation, International Journal of Innovative Technology and Exploring Engineering (IJITEE), Vol. 8, 12, pp. 2792-2794, May 2019.

60. Tarek M. Aboul-Fotouh, Sherif K. Ibrahim, M. A. Sadek, Hany A. Elazab, High Octane Number Gasoline-Ether Blend, International Journal of Innovative Technology and Exploring Engineering (IJITEE), Vol. 8, 9, pp. 732-739, March 2019.

61. Tarek M. Aboul-Fotouh, Islam Alaa, M. A. Sadek, Hany A. Elazab, Physico-Chemical Characteristics of Ethanol-Diesel Blend Fuel, International Journal of Innovative Technology and Exploring Engineering (IJITEE), Vol. 8, 9, pp. 740-747, February 2019.

62. Hany A. Elazab, M. M. Seleet, Said M. A. Hassanein, M. A. Radwan, M. A. Sadek, Synthesis and Characterization of Dinitro Pentamethylene Tetramine (DPT), Journal of Advanced Research in Dynamical and Control System, Vol. 11, 5S, pp. 310-318, August 2019.

63. Hany A. Elazab, M. M. Seleet, Said M. A. Hassanein, M. A. Radwan, M. A. Sadek, Follow-up and Kinetic Model Selection of Dinitro Pentamethylene Tetramine (DPT), International Journal of Innovative Technology and Exploring Engineering (IJITEE), Vol. 8, 8, pp. 2862-2866, October 2019.
64. Hany A. Elazab, Mamdouh Gadall, M. A. Sadek, Tamer T. El-Idreesy, Hydrothermal Synthesis of Graphene supported $\mathrm{Pd} / \mathrm{Fe}_{3} \mathrm{O}_{4}$ Nanoparticles as an Efficient Magnetic Catalysts for Suzuki Cross - Coupling, Biointerface Research in Applied Chemistry, Vol. 9, 2, pp. 3906-3911, March 2019.

65. Hany A. Elazab, M. M. Seleet, Said M. A. Hassanein, M. A. Radwan, M. A. Sadek, 3,7-Dinitro-1,3,5,7-Tetraazabicyclo[3,3,1]Nonane (DPT): An Important Intermediate in the Synthesis Route of one of the Most Powerful Energetic Materials (RDX/HMX), International Journal of Innovative Technology and Exploring Engineering (IJITEE), Vol. 8, 452, pp. 88-95, April 2019.

66. Hany A. Elazab, Tamer T. El-Idreesy, Optimization of the Catalytic Performance of $\mathrm{Pd} / \mathrm{Fe}_{3} \mathrm{O}_{4}$ Nanoparticles Prepared via Microwave-assisted Synthesis for Pharmaceutical and Catalysis Applications, Biointerface Research in Applied Chemistry, Vol. 9, 1, pp. 3794-3799, July 2019.

67. Hany A. Elazab, Yousab G. Remiz, Mostafa A. Radwan, M. A. Sadek, Synthesis and Characterization of Chitosan Based Catalyst for Catalysis Applications, International Journal of Advanced Trends in Computer Science and Engineering (IJATCSE), Volume 9, Issue 1, PP. 521-527, February 2020.

68. Hassaan M. Shehata, Dalia A. Ali, Islam M. Al-Akraa, Hoda A. Elsawy, Hany A. Elazab, Development of novel adsorbent for industrial wastewater treatment, International Journal of Advanced Trends in Computer Science and Engineering (IJATCSE), Volume 9, Issue 1, PP. 704-712, February 2020.

https://doi.org/10.30534/ijatcse/2020/100912020

69. M. H. El Dewaik, Mamdouh Gadalla, M. A. Sadek, Hany A. Elazab, Mathematica as an Efficient Tool to Optimize the Kinetic Study of Ethyl Acetate Hydrolysis, International Journal of Advanced Trends in Computer Science and Engineering (IJATCSE), Volume 9, Issue 1, PP. 691-697, February 2020.

https://doi.org/10.30534/ijatcse/2020/98912020 